\title{
DEFINIÇÃO DE METAS PARA AVALIAÇÃO DE DESEMPENHO DE AGÊNCIAS BANCÁRIAS
}

\section{GOALS DEFINITION FOR BANK AGENCIES PERFORMANCE EVALUATION}

\section{IDALBERTO JOSÉ DAS NEVES JÚNIOR}

Mestre em Gestão do Conhecimento e Tecnologia da Informação pela Universidade Católica de Brasília (UCB).

Professor e assessor pedagógico do curso de Ciências Contábeis da Universidade Católica de Brasília (UCB).

Rua Ipê Amarelo, lote 2/4, Bloco B, ap. 204, Águas Claras - Brasília - DF - CEP 71908-000

E-mail:jneves@ucb.br

\section{SOLANGE GARCIA}

Doutora em Contabilidade e Controladoria pela Universidade de São Paulo (USP). Professora adjunta do departamento de Ciências Contábeis e Atuariais da Universidade de Brasília (UnB). SQN 215, Bloco E, ap. 109 - Asa Norte - Brasília - DF - CEP 70874-050 E-mail: solangegarcia@unb.br

\section{BEATRIZ FÁTIMA MORGAN}

Mestre pelo Programa Multiinstitucional e Inter-regional em Ciências Contábeis UnB/UFPB/EFPE/UFRN.

Professora assistente do departamento de Ciências Contábeis e Atuariais da Universidade de Brasília (UnB).

SQN 411 , Bloco F, ap. 205 - Asa Norte - Brasília - DF - CEP 70866-060

E-mail: beatrizmorgan@unb.br 


\section{RESUMO}

O presente artigo tem o objetivo de verificar se as metas atribuídas às agências bancárias de uma instituição brasileira, para fins de avaliação de desempenho, são definidas de acordo com as variáveis características de sua capacidade de geração de negócios. Considerando o desempenho apresentado em 2002, são efetuadas análises de três grupos: agências que sistematicamente superam suas metas; agências que apresentam desempenho de acordo com o esperado; e agências que sistematicamente não atingem suas metas. Esses grupos são analisados em conjunto com doze agrupamentos de agências com características similares, identificados por meio da aplicação da Análise de Cluster. Os resultados apontam que as metas atribuídas às agências são coerentes com as variáveis características do potencial de geração de negócios das praças onde se situam. Contudo, para o grupo de agências que superam sistematicamente suas metas, o estudo revela que as metas subestimam o potencial das praças e agências. $O$ artigo evidencia também a contribuição da técnica de clusterização para atribuição de metas.

\section{PALAVRAS-CHAVE}

Avaliação de desempenho; Metas; Bancos; Geração de negócios; Análise de Cluster.

\section{ABSTRACT}

The present article has the objective to verify if the goals attributed to the bank agencies of a Brazilian institution for performance evaluation are defined in accordance with the variables characteristic of business generation capacity. Regarding the performance presented in 2002, analysis of tree groups are done: agencies that systematically surpass their goals; agencies that present performance in accordance with the expected; and agencies that systematically do not reach their goals. These groups are analyzed in set with I2 groupings of agencies with similar characteristics, identified based on the application of Cluster Analysis. The 
results point out that the goals attributed to the agencies are coherent with the characteristic variables of this cities business generation potencial. However, for the agencies group that surpass their goals systematically, the study discloses that the goals underestimate their cities and agencies business potencial. The article confirms the Cluster technique contribution for goals attribution.

\section{KEYWORDS}

Evaluation performance; Goals; Banking; Business generation; Cluster Analysis.

\section{INTRODUÇÃO}

O processo de definição e de atribuição de metas apresenta-se como um problema para as empresas, na medida em que não são consideradas todas as informações quando do seu estabelecimento (JENSEN, 2003). A dificuldade em estabelecer metas está presente também nos bancos (MUCCILLO NETTO, I989).

A problemática apontada pelos autores (JENSEN, 2003; MUCCILLO NETTO, I989) foi verificada em uma instituição bancária brasileira. A constatação apresentada por Neves Júnior (2003) indica que houve melhora na avaliação do resultado das agências de varejo da instituição no ano de 2002. O resultado também foi favorável na comparação entre os valores realizados no $2^{\circ}$ semestre de 2002 em relação ao $I^{\circ}$ semestre do mesmo ano. Entretanto, apesar do desempenho favorável para a instituição bancária, foram identificadas agências que sistematicamente superavam os resultados propostos e outras que, sistematicamente, não atingiam os resultados propostos. Uma análise exploratória mais detalhada evidenciou possíveis distorções na atribuição de metas, uma vez que, em determinadas agências, onde o desempenho verificado ficou abaixo do padrão orçado, foram atribuídas metas no período subseqüente acima dos padrões orçados no período anterior. Também, para determinadas agências que superaram os níveis orçados em determinado período foram, posteriormente, atribuídas metas abaixo dos padrões orçados no período anterior e, em muitos casos, abaixo dos valores realizados no período anterior. Considerando que a instituição não adota nenhuma ferramenta quantitativa e nenhum processo padronizado para atribuição de metas, o problema pode estar relacionado à projeção superestimada ou subestimada da capacidade de geração de negócios das praças onde se situam as agências bancárias.

Dessa forma, utilizando os dados do estudo de caso apresentado por Neves Júnior (2003), o objetivo deste artigo é verificar se as metas estão sendo atribuí- 
das às agências de acordo com as variáveis características de sua capacidade de geração de negócios. As variáveis consideradas incluem variáveis socioeconômicas, relativas ao mercado de atuação das agências, e variáveis relativas ao perfil da base de clientes das agências.

Para atingir tal objetivo, utilizaram-se os procedimentos de pesquisa bibliográfica e documental, com o emprego da técnica de análise estatística multivariada denominada Análise de Cluster para agrupar agências com características semelhantes, o que caracterizou a abordagem do problema como quantitativa (BEUREN et al., 2006). Os agrupamentos obtidos foram analisados em conjunto com grupos de agências definidos por meio dos níveis de desempenho apresentados no $\mathrm{I}^{\circ}$ e no $2^{\circ}$ semestres de 2002 , com destaque para os grupos de agências que apresentaram desempenho decorrente de possíveis distorções na atribuição de suas metas.

O artigo está estruturado em seis seções. Além desta Introdução, na Seção 2 encontra-se a revisão de literatura; na Seção 3 demonstram-se as características da instituição objeto do estudo; na Seção 4, a metodologia do estudo; na Seção 5, a análise dos resultados; e, por fim, a conclusão do estudo.

\section{REVISÃO DE LITERATURA}

Um papel importante do gerenciamento é assegurar que a empresa atingirá seus objetivos e, para isso, é relevante a utilização de um sistema de avaliação de desempenho (ATKINSON et al., 2000). A avaliação de desempenho nas empresas, sob um ambiente de tomada de decisão descentralizada, deve ocorrer por meio de um modelo integrado entre planejamento e controle. Tal modelo atua como facilitador da gestão da empresa como um todo e de suas partes individuais, tais como unidades de negócios, produtos e clientes (MUCCILLO NETTO, I993; ATKINSON et al., 2000).

Ainda segundo Atkinson et al. (2000, p. 587), o sistema de avaliação de desempenho coordena o comportamento da tomada de decisão, em todos os níveis da empresa. Pontes (I996) conceitua a avaliação ou administração de desempenho como um método que busca, continuamente, estabelecer um contrato pela organização, acompanhar os desafios propostos, corrigindo os rumos, quando necessário, e avaliar os resultados conseguidos.

Segundo Muccillo Netto (I993), os modelos de avaliação de desempenho e de resultados devem estar afinados com um quadro referencial - missão, objetivos, modelo de gestão, eficácia, eficiência, processo de planejamento e controle, sistemas de informações -, se não, as pessoas envolvidas sentem-se desorientadas e consideram o modelo ineficaz. 
Nessa abordagem, o orçamento apresenta-se como um instrumento de avaliação de desempenho, permitindo coordenar as atividades das unidades, bem como motivar os administradores (JENSEN, 2003). Mais especificamente, o desempenho pode ser avaliado pela análise de variações orçamentárias, obtidas pela comparação entre os resultados reais e objetivos orçados. Os desvios apresentados são analisados cuidadosamente, com o objetivo de determinar as causas das diferenças entre os valores orçados e realizados (WELSH, I983).

Para Wright et al. (2000), o processo de controle estratégico possibilita a adoção de alguns passos que visam à tomada de decisões corretivas:

Passo I: dentro do parâmetro da missão e dos objetivos gerais e específicos da organização, determinar que necessidades devem ser monitoradas, avaliadas e controladas.

Passo 2: estabelecer padrões.

Passo 3: mensurar o desempenho.

Passo 4: comparar desempenho com padrões.

Passo 5: não tomar medida alguma se o desempenho se harmonizar com os padrões.

Passo 6: tomar medidas corretivas se o desempenho não se harmonizar com os padrões.

Dessa forma, o processo de controle estratégico ocorre por meio da comparação com padrões previamente definidos; no entanto, o estabelecimento desses padrões (metas) emerge como um problema. Segundo Anthony e Govindarajan (2002, p. 476), "o orçamento ideal é aquele que constitui um desafio, mas é exeqüível”. Os autores apontam algumas razões em favor de se determinarem metas exeqüíveis para as unidades:

a. Se a meta orçada é muito difícil de ser alcançada, os executivos são levados a tomar decisões de alcance a curto prazo que não se coadunam com os interesses a longo prazo da empresa".

b. "Metas orçadas exeqüíveis reduzem a tentação dos executivos de manipulação dos dados".

c. Se os lucros orçados são metas exeqüíveis, tais metas podem ser divulgadas entre os analistas de mercado financeiro, acionistas e outros interessados com razoável confiança.

d. Um lucro orçado difícil de ser alcançado pode levar a um comprometimento exagerado de recursos, a fim de aumentar as vendas.

e. Quando as unidades conseguem cumprir ou ultrapassar as suas metas, é criado um clima de atitudes positivas na empresa. 
Muccillo Netto (1989), em seu estudo, reconhece que o orçamento é um verdadeiro instrumento de congruência de metas, uma vez que as propostas orçamentárias dos centros de responsabilidade são integradas ao orçamento global da empresa. Todavia, admite que o processo orçamentário apresenta uma série de problemas. Há uma tendência natural de autoproteção dos centros de responsabilidade em deliberar metas orçamentárias em níveis altos ou baixos, segundo o seu interesse, não deixando margem quanto à sua exeqüibilidade.

Segundo Jensen (2003), o problema está nas metas estabelecidas. Os gerentes estabelecem metas baixas para que sejam cumpridas, e quando agressivas e exageradas, são tomadas, muitas vezes, decisões equivocadas para cumpri-las, prejudicando a empresa.

Como possibilidade de minimizar o problema, poder-se-á utilizar de métodos quantitativos para a definição das metas, a exemplo da análise de Cluster, a qual consiste em entender a estrutura dos dados, aglomerando observações similares em grupos (FRALEY; RAFTERY, 2005). A sua aplicação é, portanto, bastante imediata e pode conferir um bom poder exploratório à medida que as decisões sejam tomadas sobre formas alternativas para mensuração de similaridades, critérios de formação de grupos e número ideal de grupos a serem formados. Alguns estudos demonstram a aplicação dessa análise no ambiente empresarial.

Galbraith e Jiaqing (2005) aplicaram a técnica de análise de Cluster e a análise discriminante para o estudo do desempenho entre as indústrias que possuíam características similares. A pesquisa resultou na organização dos dados das indústrias em grupos similares e análise do desempenho entre elas.

Crocco et al. (2005) realizaram uma pesquisa objetivando definir um cenário espacial de acesso bancário e preferência pela liquidez do público do Estado de Minas Gerais, com base na divisão em mesorregiões geográficas do Instituto Brasileiro de Geografia e Estatística (IBGE). A base teórica utilizada foi a teoria pós-keynesiana, a qual sugere que regiões com alta preferência de liquidez e baixo acesso bancário são supostas a apresentar problemas de crédito, o que dificulta seu desenvolvimento. Para análise dos dados utilizaram-se duas técnicas estatísticas de análise multivariada: a análise dos componentes principais (ACP) e a análise de Cluster. A pesquisa permitiu identificar que há uma clara separação geográfica entre mesorregiões em termos de acesso bancário e preferência pela liquidez do público.

Para o gerenciamento das metas das empresas, um instrumento de grande relevância é o Balanced Scorecard (BSC). Esse modelo de gestão traduz a missão e a estratégia em objetivos e medidas, organizados segundo quatro perspectivas diferentes: financeira, do cliente, dos processos internos, e da inovação e 
aprendizado. O Scorecard cria uma estrutura, uma linguagem, para comunicar a missão e a estratégia, e utiliza indicadores para informar os funcionários sobre os vetores do sucesso atual e futuro. Ao articularem os resultados desejados pela empresa com os vetores desses resultados, os executivos esperam canalizar as energias, as habilidades e os conhecimentos específicos nas pessoas na empresa inteira, para alcançar as metas de longo prazo (KAPLAN; NORTON, I997).

O Balanced Scorecard possibilita e favorece a implementação de ações para obter feedback sobre a estratégia - lacuna existente na maioria dos sistemas gerenciais. No entanto, têm-se algumas dificuldades em implementar e executar as estratégias traçadas pela alta administração, dentre elas: falha na comunicação, falta de medidas que possam avaliar o desempenho, e falta de visão corporativa por parte dos administradores. Segundo Davis e Albright (2004), o BSC aumenta a necessidade de planejamento, de controle e a função de mensuração de desempenho.

O Balanced Scorecard inclui variáveis não financeiras na mensuração do desempenho, e a eficácia de tais medidas é discutida em pesquisas da área. Para Hussain e Gunasekaran (2002), as variáveis de desempenho financeiro, tais como lucro, receita, taxa de retorno, ainda recebem maior atenção na avaliação de desempenho dos bancos. No entanto, Davis e Albright (2004) compararam o desempenho financeiro de divisões de um banco antes e depois da implementação do BSC. O estudo apresentou evidências de que o BSC pode melhorar o desempenho financeiro.

\section{CARACTERÍSTICAS DO MODELO DE AVALIAÇÃO DA INSTITUIÇÃ̃O BANCÁRIA}

A pesquisa ora apresentada tem como base o estudo de caso de Neves Júnior (2003). Com base nos dados apresentados pelo autor, são realizadas as análises para atingir o objetivo proposto.

A instituição bancária brasileira, fonte dos dados considerados, tem como funções a prática de todas as operações bancárias ativas, passivas e acessórias e a prestação de serviços bancários. A instituição está organizada para atendimento dos segmentos de mercado denominados de Varejo, Atacado e Governo, compostos, respectivamente, por clientes pessoas físicas e clientes pessoas jurídicas classificados como micro e pequenas empresas; clientes pessoas jurídicas classificados como médias, grandes e megaempresas, e clientes do setor público das esferas municipal, estadual e federal. 
A instituição adota os conceitos do modelo de gestão estratégica BSC para divulgação de sua estratégia, para comunicação de metas e para o controle e avaliação de desempenho de todas as suas unidades organizacionais. Para as agências bancárias o modelo é denominado Contrato de Gestão, e é composto pelas perspectivas: Resultado, Estratégia, Clientes, Processos e Aprendizado. A Tabela I apresenta comparativo das perspectivas recomendadas no BSC com o modelo adotado pela instituição:

\section{TABELA I}

COMPARAÇÃO DAS PERSPECTIVAS DO BSC

\begin{tabular}{ll}
\multicolumn{1}{c}{$\begin{array}{c}\text { MODELO BSC - KAPLAN E NORTON (1997) } \\
\text { PERSPECTIVAS }\end{array}$} & \multicolumn{1}{c}{ MODELO BSC - ADOTADO } \\
Financeira & Resultado \\
\hline & Estratégia \\
\hline Cliente & Cliente \\
\hline Interna & Processos \\
\hline Inovação e Aprendizado & Aprendizado \\
\hline
\end{tabular}

Fonte: Elaboração própria.

Cada uma das perspectivas é composta por indicadores, para os quais são definidas metas com base em volumes e quantidades orçadas. Cada indicador possui um peso (porcentual) de acordo com o seu grau de importância na perspectiva. O desempenho em cada um dos indicadores é verificado em razão do desvio porcentual entre os valores realizados e os valores orçados (meta) para o período. De acordo com a variação do atingimento em torno da meta é atribuída uma nota que varia de i a 6 , conforme Tabela 2 . 
TABELA 2

PONTUAÇÃO DOS INDICADORES

\begin{tabular}{lrrrrll}
\hline \multicolumn{2}{c}{ DESVIO OU ATINGIMENTO } & NOTA & \multicolumn{1}{c}{ DESEMPENHO } \\
\hline De & $-\infty$ & a & $-25,01 \%$ & 1 & Insuficiente \\
\hline De & $-25,00 \%$ & a & $-15,01 \%$ & 2 & Abaixo do esperado \\
\hline De & $-15,00 \%$ & a & $-5,01 \%$ & 3 & Pouco abaixo do esperado \\
\hline De & $-5,00 \%$ & a & $4,99 \%$ & 4 & Esperado \\
\hline De & $5,00 \%$ & a & $15,00 \%$ & 5 & Acima do esperado \\
\hline De & $15,01 \%$ & a & $\infty$ & 6 & Excepcional \\
\hline
\end{tabular}

Fonte: Elaboração própria.

A pontuação de cada perspectiva é obtida pela média ponderada da nota de cada indicador pelo seu respectivo peso. Cada perspectiva, contudo, também possui um peso, e esses pesos somados totalizam ioo pontos. A pontuação do placar geral da agência é obtida pela média ponderada da nota de cada perspectiva pelo seu respectivo peso, variando de Ioo a 600 pontos. O desempenho das unidades, consolidado no placar geral, habilita a agência no programa de participação nos lucros e resultados da empresa.

A modelagem do Contrato de Gestão das agências é efetuada pela Unidade de Controladoria, em conjunto com a Unidade Gestora da Rede de Agências. Esse processo envolve a definição dos indicadores que comporão cada uma das perspectivas, da importância relativa dos indicadores e perspectivas no placar geral de desempenho da unidade (pesos de indicadores e de perspectivas) e a forma de pontuação de cada um deles.

A definição de indicadores ocorre antes do início do período avaliativo - que tem periodicidade semestral - e decorre do processo de planejamento da instituição, no qual são definidos planos por diretoria e por segmentos de atuação no mercado. Esses planos são aderentes ao Planejamento Estratégico da Empresa e são os principais instrumentos, juntamente com os Orçamentos, para elaboração dos Contratos de Gestão.

Com base na elaboração dos orçamentos de volumes e quantidades de produtos e serviços, bem como de despesas administrativas, a Unidade Gestora da Rede distribui as metas por unidades gestoras estaduais, que, por sua vez, distribuem as metas para unidades regionais, as quais repassam as metas para suas agências jurisdicionadas. Não existe um procedimento padrão da instituição para 
definição das metas em cada uma das unidades gestoras. Essa definição se fundamenta nas informações disponíveis, na experiência dos gestores e no processo de negociação que ocorre entre gestores de rede estaduais, regionais e as respectivas agências avaliadas.

Tendo em vista que, de acordo com a relação de causa e efeito, a perspectiva financeira consolida o desempenho das demais perspectivas e apresenta, na instituição analisada, participação porcentual de $60 \%$ no placar geral das agências, foi efetuada análise do desempenho das agências na perspectiva Resultado no I ${ }^{\circ}$ e no $2^{\circ}$ semestres de 2002.

As agências obtiveram no período desempenho predominantemente de superação de metas. No I ${ }^{\circ}$ semestre de 2002 , I $2 \%$ das agências atingiram o desempenho em torno das metas esperadas, e $89 \%$ das agências superaram as metas, obtendo nota acima de 4 na perspectiva Financeira. No $2^{\circ}$ semestre de 2002 , 4\% das agências obtiveram nota 4 , e $96 \%$ das agências obtiveram nota acima de 4 na perspectiva. O desvio positivo entre o resultado financeiro observado e o resultado financeiro orçado representou $33 \%$ no I semestre de 2002 , e $49,6 \%$ no $2^{\circ}$ semestre de 2002.

$\mathrm{Na}$ comparação do desempenho do $\mathrm{I}^{\circ}$ e do $2^{\circ}$ semestres de 2002 o resultado global evoluiu em 9,2\%. Também, quando se analisa o desempenho nos itens componentes do resultado, a avaliação é favorável, conforme ilustra a Tabela 3. A margem financeira bruta evoluiu 3\%, enquanto as despesas administrativas e os custos variáveis aumentaram, respectivamente, I0,7\% e I,2\%. Contudo, os resultados indicam a adoção de estratégias que resultaram na otimização das receitas e de suas deduções (provisão para crédito de liquidação duvidosa, despesas administrativas e custos variáveis), que possibilitaram incremento porcentual no resultado consolidado das agências. 


\section{TABELA 3}

COMPARAÇÃO DO DESEMPENHO:

$2^{\circ} \mathrm{SEM}$. EM RELAÇÃO AO I ${ }^{\circ} \mathrm{SEM} .2002$

\begin{tabular}{lc}
\hline & VARIAÇÃO \\
\cline { 2 - 2 } COMPONENTE & $\%$ \\
\hline Margem Financeira Bruta & $3,0 \%$ \\
\hline Receita de Serviços & $-0,3 \%$ \\
\hline Pcld & $-12,8 \%$ \\
\hline Despesas Administrativas & $10,7 \%$ \\
\hline Custos Variáveis / Acessórios / Outros & $1,2 \%$ \\
\hline Serviços Internos e Royalties & $-6,6 \%$ \\
\hline Resultado & $9,2 \%$ \\
\hline
\end{tabular}

Fonte: Elaboração própria.

Em razão, contudo, do excelente desempenho apresentado, especialmente em virtude do porcentual significativo de unidades que superaram suas metas, procedeu-se à análise exploratória da base de informações de desempenho das agências abrangendo inclusive períodos anteriores a 2002. Nessa análise foram identificadas, de forma pontual, agências que vinham superando os resultados propostos em vários períodos, e outras que, sistematicamente, não vinham atingindo os resultados propostos.

Além disso, procedeu-se à análise dos resultados realizados vis-à-vis os resultados orçados nos períodos seguintes para essas unidades. Foram identificadas agências nas quais o desempenho verificado em um período ficou abaixo do padrão orçado e as metas atribuídas no período subseqüente estavam acima dos padrões orçados no período anterior. Também, para determinadas agências que superaram os níveis orçados em determinado período, foram atribuídas metas abaixo dos padrões orçados no período anterior e, em muitos casos, abaixo dos valores realizados no período anterior. 


\section{METODOLOGIA}

Para analisar as características do desempenho apresentado pelas agências em relação aos valores orçados pelos administradores, foi efetuado tratamento empírico dos dados de desempenho da instituição financeira referente ao $\mathrm{I}^{\circ} \mathrm{e}$ ao $2^{\circ}$ semestres de 2002, e ao I semestre de 2003, contemplando todas as agências da instituição (3.100 agências após tratamento da base). O sistema de informações contém os valores orçados e realizados de cada um dos componentes do indicador Resultado da perspectiva Financeira do BSC da instituição.

De acordo com os possíveis problemas identificados na análise exploratória dos resultados da avaliação de desempenho no ano de 2002, as agências foram classificadas em três grupos de desempenho. Esses grupos foram definidos considerando a evolução do atingimento do resultado em relação às metas orçadas em três semestres consecutivos. O período foi escolhido pela sua uniformidade em termos dos critérios adotados para avaliação, uma vez que a instituição costuma promover alterações e ajustes no modelo de um período para outro.

Grupo 1 - Agências que superam sistematicamente o padrão esperado: agências cujo atingimento no valor realizado $(R)$ do indicador Resultado da agência foi superior a $5 \%$ por dois semestres consecutivos, e, mesmo assim, o novo valor esperado $(O)$ teve queda superior a $20 \%$ em relação ao último valor realizado.

$(R) \mathrm{I}^{\mathrm{o}}$. semestre de $2002 \mathrm{X}(O) \mathrm{I}^{\mathrm{o}}$. semestre $2002 \geq 5 \%$

$(R) 2^{\circ}$. semestre de $2002 \mathrm{X}(O) 2^{\circ}$. semestre $2002 \geq 5 \%$

(O) $\mathrm{I}^{\circ}$. semestre de $2003 \mathrm{X}(\mathrm{O}) 2^{\circ}$. semestre $2002 \leq 20 \%$

Grupo 2 - Agências que sistematicamente não atingem o padrão esperado: agências que não atingiram o valor esperado $(O)$ por dois semestres consecutivos, com desvios superiores a $5 \%$, e, mesmo assim, no período seguinte, o valor esperado aumentou mais de $5 \%$.

$(R) \mathrm{I}^{\circ}$. semestre de $2002 \mathrm{X}(O) \mathrm{I}^{\circ}$. semestre $2002 \leq 5 \%$

$(R) 2^{\circ}$. semestre de $2002 \mathrm{X}(O) 2^{\circ}$. semestre $2002 \leq 5 \%$

$(O) I^{\circ}$. semestre de $2003 X(O) 2^{\circ}$. semestre $2002 \geq 5 \%$

Grupo 3 - Agências que apresentam resultados de acordo com o comportamento esperado, ou seja, podem eventualmente superar as metas em um semestre e não superar em outro, e vice-versa. Também, o comportamento dos valores orçados no $3^{\circ}$. semestre pode ser superior ou inferior ao semestre anterior, o 
que de fato pode ocorrer em razão de situações circunstanciais de cada praça ou agência.

Com o objetivo de agrupar as agências com características semelhantes, foi utilizada a técnica de análise estatística multivariada denominada Análise de Cluster, sobre uma amostra composta por variáveis relativas ao ambiente socioeconômico (dimensão externa) e sobre as características dos clientes das agências (dimensão interna). Para a dimensão externa, foram utilizadas 50 variáveis representativas do dinamismo econômico, do mercado financeiro, do grau de desenvolvimento social e da demografia dos municípios de atuação das agências. A dimensão interna foi representada por I3 variáveis relativas a quantidade e participação porcentual dos segmentos de clientes pessoa física, jurídica, governo, na base de clientes das agências.

Os dados das variáveis da dimensão externa (50 variáveis) foram coletados das bases do IBGE do período de I996 a 200I, e os dados das variáveis da dimensão interna foram obtidos no sistema de informação da instituição, com posição de dezembro de 200 I.

A aplicação da Análise de Cluster exige que as variáveis do modelo não sejam altamente correlacionadas. Para verificar o efeito da correlação entre as variáveis e definir fatores não correlacionados, foi aplicada a técnica denominada Análise Fatorial, utilizando-se o método ACP-Análise de Componentes Principais com rotação Varimax, em cada uma das duas dimensões separadamente. Como resultado desse procedimento, foram criados oito fatores externos e quatro fatores internos:

\section{Fatores da dimensão externa}

a. Porte: Total da população; PIB industrial; PIB comercial; PIB de serviços; Total de empresas; Total de agências bancárias; Total de depósitos na praça; Total de operações de crédito na praça; Receita orçamentária municipal; Servidores públicos.

b. Desenvolvimento socioeconômico: Índice de condição de vida - longevidade; Índice de condição de vida - educação; Índice de condição de vida - infância; Índice de condição de vida - renda; Índice de condição de vida - habitação; \% População 20 a 60 anos; \% População urbana; \% estabelecimentos agropecuários de Io ha a Ioo ha; \% estabelecimentos agropecuários com energia elétrica; \% População até I9 anos; Número de habitantes por agência bancária; \% de bancos públicos na praça.

c. Estrutura agrária: \% estabelecimentos agropecuários de Io० ha a 200 ha; \% estabelecimentos agropecuários de 200 ha a 500 ha; \% estabelecimentos agropecuários de 500 ha a 2000 ha; \% estabelecimentos pecuários; \% estabelecimentos agrícolas; \% estabelecimentos agropecuários até ıo ha. 
d. Indústria e emprego: \% PIB industrial; \% empresas - 5 a Io pessoas; \% empresas - IO a 20 pessoas; \% empresas - 20 a 30 pessoas; $\%$ empresas - 30 a 50 pessoas; \% empresas -50 a Ioo pessoas.

e. Atividade de serviços: \% PIB serviços; \% PIB agropecuário.

f. Atividade agropecuária: PIB agropecuário; Total de estabelecimentos agropecuários; Total de tratores no município; \% empresas - I00 a 200 pessoas.

g. Concentração de negócios bancários: Depósitos por agência bancária; Operações de crédito por agência bancária.

h. Microempresas: \% empresas - I a 4 pessoas; \% empresas sem empregados.

\section{Fatores da dimensão interna}

a. Varejo: \% de clientes pessoa física - clientes A; \% de clientes pessoa física - clientes B; \% de clientes pessoa física - demais clientes pessoa física; \% de clientes pessoa jurídica - micro e pequenas empresas.

b. Atacado: \% de clientes pessoa jurídica - médias empresas; \% de clientes pessoa jurídica - grandes empresas; \% de clientes pessoa jurídica - megaempresas.

c. Escala de clientes: Total de clientes pessoa física; Total de clientes pessoa jurídica; Total de clientes setor público.

d. Governo: \% de clientes setor público - esfera municipal; \% de clientes setor público - esfera estadual; \% de clientes setor público - esfera federal.

A Análise de Cluster - método não hierárquico (K-means clustering, no software SPSS) - foi aplicada formando-se inicialmente 20 clusters com escolha aleatória dos seus centros, e depois selecionando-se os I2 clusters mais representativos, excluindo os centros dos grupos formados por outliers. O outlier foi caracterizado pela sua relação com os dados restantes que fazem parte da população analisada e aplicou-se novamente a mesma técnica para formação de I2 clusters, fixando os centros iniciais com os valores referentes aos grupos selecionados anteriormente. O Método Probabilístico Alternativo (Análise Discriminante do software SPSS) foi utilizado para verificar se as agências foram classificadas corretamente nos clusters.

Finalmente, foi efetuado o cruzamento dos dados obtidos nos dois procedimentos anteriores: as agências classificadas em cada um dos I2 clusters com as agências pertencentes aos três grupos de desempenho definidos (Grupo I, 2 e 3). O objetivo da análise foi verificar se há características semelhantes entre as agências que tiveram possível dificuldade ou facilidade no atingimento de suas metas, bem como identificar a existência de alguma relação entre os desvios apresentados pelas agências e os seus respectivos agrupamentos com características semelhantes (socioeconômica e perfil da clientela). 


\section{ANÁlise dos Resultados}

A análise dos grupamentos de desempenho das agências evidenciou que I9,6\% das agências superam sistematicamente o padrão esperado (Grupo I), $0,4 \%$ das agências sistematicamente não atingem o padrão esperado (Grupo 2), e $80 \%$ das agências têm apresentado resultados dentro do desempenho esperado ao longo dos períodos analisados, de acordo com os parâmetros definidos para os agrupamentos.

É importante salientar que, no Grupo 2, o número de agências que sistematicamente não atingem o padrão esperado é pouco expressivo em relação ao total das agências do país (0,4\% das agências). Não obstante, especialmente em razão do fator motivacional do quadro funcional daquelas dependências, é importante analisar as causas prováveis do desempenho abaixo do esperado. O problema pode estar relacionado à projeção superestimada da capacidade das agências e de seu mercado de atuação.

O Grupo I revela número significativo de agências que superam sistematicamente o padrão esperado ( $20,1 \%$ das agências) e ocorre redução das metas nos períodos subseqüentes. Esse resultado confirma a necessidade de um estudo mais detalhado para buscar as causas prováveis da superação do padrão esperado e as possíveis deficiências no processo de atribuição de metas. O problema pode estar relacionado à projeção subestimada da capacidade das agências e de seu mercado de atuação. A investigação é relevante porque, apesar do aparente bom desempenho, as metas podem não ter sido desafiadoras e o desempenho alcançado estar aquém da contribuição potencial dessas agências ao resultado global da instituição.

A aplicação da Análise de Cluster definiu os I2 agrupamentos seguintes, cuja análise dos resultados do agrupamento de agências efetuado permitiu fazer a seguinte caracterização:

Cluster I - Grupo composto por grandes e médias agências com mercado potencial de grande porte, bom desenvolvimento socioeconômico, boa estrutura agrária e grande porcentual de microempresas. Há predominância de clientes com perfil Varejo e Atacado.

Cluster 2 - Grandes, médias e pequenas agências com mercado potencial de grande porte, bom desenvolvimento socioeconômico; predominância de indústria, serviços e atividade agropecuária; boa estrutura agrária e grande percentual de microempresas. A base de clientes apresenta perfil de Varejo.

Cluster 3 - Apenas duas agências com perfil de Atacado com mercado potencial de grande porte; emprego, indústria e serviços desenvolvidos, bom 
desenvolvimento socioeconômico, boa estrutura agrária e atividade agropecuária e grande porcentual de microempresas. Há predominância de clientes com perfil de Atacado.

Cluster 4 - Pequenas agências com mercado potencial de pequeno porte, excelente desenvolvimento socioeconômico, concentração de negócios bancários, grande porcentual de microempresas e boa estrutura agrária e atividade agropecuária. A base de clientes é diversificada, com perfil de Varejo, Atacado, Governo e do segmento Rural.

Cluster 5-Grandes, médias e pequenas agências situadas em pólos desenvolvidos com mercado potencial de médio porte, desenvolvimento socioeconômico médio, concentração de negócios, destaque de empregos, presença de indústrias e serviços. Há predominância de clientes com perfil de Varejo.

Cluster 6 - Grandes, médias e pequenas agências em cidades de médio porte com mercado potencial de baixo porte, desenvolvimento socioeconômico razoável, pouca concentração de negócios bancários; destaque de empregos, indústria e serviços e participação de microempresas. A base de clientes não apresenta perfil definido, destaque para o número de contas pessoas física e jurídica.

Cluster 7 - Grandes, médias e pequenas agências com mercado potencial de grande porte; presença de serviços, atividade agropecuária e alta concentração de negócios bancários. A base de clientes apresenta perfil de Varejo e Governo.

Cluster 8 - Grandes agências em grandes cidades situadas em todas as regiões do país. Mercado potencial de médio porte; bom índice de emprego; presença de indústria, serviços e atividade agrária. A base de clientes apresenta alta escala de contas pessoas física e jurídica.

Cluster 9 - Agências distribuídas em todas as regiões do país. Mercado potencial de forte estrutura agrária e forte presença de microempresas. A base de clientes apresenta baixa escala de contas pessoas física e jurídica.

Cluster Io - Concentração de médias agências do interior dos Estados, com mercado potencial de alto desenvolvimento socioeconômico, alto nível de atividade agropecuária e concentração de negócios. A base de clientes apresenta alta escala de contas pessoas física e jurídica.

Cluster II - Pequenas agências do interior com mercado potencial de baixo desenvolvimento socioeconômico, grande ocorrência de contratos de Governo, presença de microempresas e serviços. A base de clientes apresenta alta escala de contas pessoas física e jurídica.

Cluster I2 - Grandes agências situadas em capitais com mercado potencial de grande porte, médio desenvolvimento socioeconômico, presença de empregos, indústria e serviços. A base de clientes possui forte concentração do perfil Atacado, gerando alta escala de contas pessoas física e jurídica. 
A análise dos dados foi validada por método probabilístico alternativo, apresentando um índice médio de $85 \%$ de acertos de classificação, conforme Tabela 4 .

\section{TABELA 4}

VALIDAÇÃO DA METODOLOGIA DE CLUSTERS

\begin{tabular}{cccccccccccccc}
\hline \multirow{2}{*}{$\begin{array}{c}\text { CLUSTER } \\
\text { PROPOSTO }\end{array}$} & 1 & 2 & 3 & 4 & 5 & 6 & 7 & 8 & 9 & 10 & 11 & 12 \\
\hline 1 & 85,24 & 0,74 & 0,00 & 2,21 & 2,58 & 6,27 & 0,00 & 1,11 & 1,85 & 0,00 & 0,00 & 0,00 \\
\hline 2 & 5,50 & 84,54 & 6,87 & 0,00 & 0,00 & 2,75 & 0,00 & 0,00 & 0,00 & 0,34 & 0,00 & 0,00 \\
\hline 3 & 0,00 & 2,36 & 89,83 & 0,00 & 0,00 & 6,15 & 1,42 & 0,24 & 0,00 & 0,00 & 0,00 & 0,00 \\
\hline 4 & 0,89 & 0,00 & 0,00 & 87,74 & 0,53 & 2,13 & 3,55 & 1,07 & 4,09 & 0,00 & 0,00 & 0,00 \\
\hline 5 & 4,10 & 0,51 & 0,00 & 4,62 & 83,08 & 2,56 & 0,00 & 0,00 & 5,13 & 0,00 & 0,00 & 0,00 \\
\hline 6 & 2,74 & 0,39 & 5,28 & 2,54 & 1,37 & 83,56 & 2,74 & 0,20 & 1,17 & 0,00 & 0,00 & 0,00 \\
\hline 7 & 0,00 & 0,00 & 1,80 & 10,02 & 0,00 & 5,81 & 80,96 & 1,20 & 0,20 & 0,00 & 0,00 & 0,00 \\
\hline 8 & 1,64 & 0,66 & 0,00 & 4,59 & 0,00 & 1,64 & 3,93 & 85,25 & 1,97 & 0,33 & 0,00 & 0,00 \\
\hline 9 & 8,85 & 0,00 & 0,00 & 6,19 & 0,88 & 3,54 & 0,88 & 5,31 & 74,34 & 0,00 & 0,00 & 0,00 \\
\hline 10 & 1,20 & 8,43 & 0,00 & 0,00 & 0,00 & 0,00 & 0,00 & 2,41 & 2,41 & 85,54 & 0,00 & 0,00 \\
\hline 11 & 0,00 & 0,00 & 0,00 & 0,00 & 0,00 & 0,00 & 0,00 & 0,00 & 3,77 & 0,00 & 96,23 & 0,00 \\
\hline 12 & 0,00 & 0,00 & 0,00 & 0,00 & 0,00 & 0,00 & 0,00 & 0,00 & 0,00 & 0,00 & 11,11 & 88,89 \\
\hline
\end{tabular}

Fonte: Elaboração própria.

A distribuição porcentual das agências em seus respectivos clusters é apresentada na Tabela 5. Os maiores porcentuais são identificados no Cluster 4 (20\% das agências), Cluster 5 (13\% das agências), Cluster 6 (ıо\% das agências), Cluster 8 (9\% das agências), Cluster 9 (I3\% das agências) e Cluster II (I7\% das agências). 
TABELA 5

DISTRIBUIÇÃO DAS AGÊNCIAS BANCÁRIAS EM CLUSTERS

\begin{tabular}{cccccccccccccc}
\hline CLUSTERS & 1 & 2 & 3 & 4 & 5 & 6 & 7 & 8 & 9 & 10 & 11 & 12 & TOTAL \\
\hline$\%$ & $5 \%$ & $5 \%$ & $0 \%$ & $20 \%$ & $13 \%$ & $10 \%$ & $4 \%$ & $9 \%$ & $13 \%$ & $6 \%$ & $17 \%$ & $1 \%$ & $100 \%$ \\
\hline
\end{tabular}

Fonte: Elaboração própria.

A Tabela 6 apresenta o resultado do cruzamento dos dados, identificando a participação porcentual dos três grupos de desempenho em cada um dos I2 clusters definidos. Em termos porcentuais, há predominância em todos os clusters do agrupamento de agências que se situam dentro do padrão esperado de desempenho (Grupo 3).

\section{TABELA 6}

PARTICIPAÇÃO DOS GRUPOS DE DESEMPENHO NOS CLUSTERS DE AGÊENCIAS

\begin{tabular}{|c|c|c|c|c|}
\hline \multicolumn{5}{|c|}{ GRUPAMENTO } \\
\hline CLUSTERS & GRUPO 1 & GRUPO 2 & GRUPO 3 & TOTAL \\
\hline 1 & $20,57 \%$ & $0,00 \%$ & $79,43 \%$ & $100,00 \%$ \\
\hline 2 & $13,14 \%$ & $0,73 \%$ & $86,13 \%$ & $100,00 \%$ \\
\hline 3 & $33,33 \%$ & $0,00 \%$ & $66,67 \%$ & $100,00 \%$ \\
\hline 4 & $16,81 \%$ & $0,00 \%$ & $83,19 \%$ & $100,00 \%$ \\
\hline 5 & $22,45 \%$ & $0,26 \%$ & $77,28 \%$ & $100,00 \%$ \\
\hline 6 & $18,54 \%$ & $0,99 \%$ & $80,46 \%$ & $100,00 \%$ \\
\hline 7 & $17,92 \%$ & $1,89 \%$ & $80,19 \%$ & $100,00 \%$ \\
\hline 8 & $13,85 \%$ & $0,00 \%$ & $86,15 \%$ & $100,00 \%$ \\
\hline 9 & $24,60 \%$ & $0,27 \%$ & $75,13 \%$ & $100,00 \%$ \\
\hline 10 & $15,17 \%$ & $0,00 \%$ & $84,83 \%$ & $100,00 \%$ \\
\hline 11 & $27,11 \%$ & $0,60 \%$ & $72,29 \%$ & $100,00 \%$ \\
\hline 12 & $4,76 \%$ & $0,00 \%$ & $95,24 \%$ & $100,00 \%$ \\
\hline Total & $20,03 \%$ & $0,37 \%$ & $79,6 \%$ & $100,00 \%$ \\
\hline
\end{tabular}

Fonte: Elaboração própria. 
Considerando o porcentual de agências em cada um dos clusters (Tabela 5), os dados da Tabela 6 revelam que as agências que superaram sistematicamente o padrão esperado (Grupo I) estão mais concentradas, respectivamente, nos clusters II (4,59\% do total de agências), 4 (3,4\% do total de agências), 9 (3,25\% do total de agências) e 5 ( $2,86 \%$ do total de agências). As agências classificadas nesses clusters têm, de fato, condições socioeconômico favoráveis para o cumprimento e a superação de suas metas, exceto aquelas classificadas no cluster II, que apresentam mercado potencial de baixo desenvolvimento socioeconômico; porém, com grande ocorrência de contratos de Governo.

O número de agências que sistematicamente não atingem o padrão esperado (Grupo 2) é ínfimo para todos os clusters analisados. As agências que têm apresentado desempenho de acordo com o esperado (Grupo 3) estão mais concentradas, em número de agências, respectivamente, nos clusters 4, 5 e II.

\section{CONCLUSÃO}

A análise dos grupos de desempenho em conjunto com os clusters permite concluir que a modelagem de avaliação de desempenho das agências bancárias de varejo da instituição pesquisada é, em grande proporção, coerente com a sua capacidade de geração de negócios. Essa capacidade foi definida por meio das variáveis relativas ao ambiente socioeconômico no qual a agência está inserida e das variáveis relativas à sua base de clientes. O resultado é evidenciado pela predominância de agências com desempenho de acordo com o esperado, revelando que os padrões de desempenho atribuídos, embora não sendo decorrentes de modelos quantitativos, conseguem captar os aspectos que estão refletidos nos clusters identificados.

A análise também permite concluir que, para parcela significativa das agências, as metas atribuídas estão aquém de sua capacidade em termos de potencial de clientes e de mercado de atuação. Esse fato é comprovado pelo maior número de agências que sistematicamente superam suas metas situadas nos clusters com boas condições socioeconômicas. Além disso, a evolução das metas ao longo dos três períodos da análise, as quais apresentam comportamento decrescente em relação aos valores realizados, denota desconhecimento do potencial das praças e clientes e outras possíveis dificuldades no processo ou no sistema de informações internas da instituição bancária.

Embora os resultados apontem porcentual pouco expressivo de agências que sistematicamente não atingem o padrão esperado, é importante considerar as causas prováveis do baixo desempenho. Como o sistema de avaliação de desempenho tem impacto no sistema de recompensas dos empregados, as possíveis 
distorções do processo podem causar desestímulo e comprometer a credibilidade do sistema.

Também é importante destacar a técnica estatística de clusterização como ferramenta que pode ser adotada para atribuição de metas. No presente estudo, a aplicação da técnica possibilitou a identificação de I2 clusters de agências com características similares. A adoção da ferramenta pode contribuir para a melhoria do processo de atribuição de metas, especialmente para grandes redes nacionais e internacionais que possuem unidades espalhadas em regiões com características diversificadas.

\section{REFERÊNCIAS}

ANTHONY, R. N.; GOVINDARAJAN, V. Sistemas de controle gerencial. São Paulo: Atlas, 2002. ATKINSON, A. A. et al. Contabilidade gerencial. São Paulo: Atlas, 2000.

BEUREN, I. M. et al. Como elaborar trabalhos monográficos em Contabilidade - Teoria e prática. 3. ed. São Paulo: Atlas, 2006.

CROCCO, M. et al. Acesso bancário e preferência pela liquidez nas mesorregiões de Minas Gerais. Disponível em: <http://www.cedeplar.ufmg.br/diamantina2002/textos/D27.PDF>. Acesso em: 22 jun. 2005.

DAVIS, S.; ALBRIGHT, T. An investigation of the effect of Balanced Scorecard Implementation on financial performance. Management Accounting Research, v. I5, p. I35-I53, 2004.

FRALEY, C.; RAFTERY, A. E. How many clusters? Wish clustering method? Answers via Model-Based Cluster Analysis. Disponível em: <http://lib.stat.cmu.edu/S/mclust/tr329.pdf>. Acesso 22 jun. 2005 .

GALBRAITH, J. K.; JIAQING, L. Cluster and discriminant analysis on time-series as a Research Tool. Disponível em: <http://papers.ssrn.com/sol3/papers.cfm?abstract_id=228678>. Acesso 22 jun. 2005 .

HUSSAIN, M.; GUNASEKARAN, A. Management accounting and performance measures in Japanese banks. Managing Service Quality, v. I2, n. 4, 2002.

JENSEN, M. C. Paying people to lie: the truth about the budgeting process. European Financial Management, v. 9, n. 3, p. 379-406, 2003.

KAPLAN, R. S.; NORTON, D. P. A estratégia em ação: Balanced Scorecard. I3. ed. Rio de Janeiro: Campus, I997.

MUCCILLO NETTO, J. Contribuição à análise de problemas de utilização de modelos de avaliação de desempenho e de resultados em instituições financeiras. São Paulo, I989. Tese (Doutorado em Administração) - Faculdade de Economia, Administração e Contabilidade, Universidade de São Paulo.

Avaliação de desempenho de instituições financeiras. Revista de Administração, São Paulo, v. 28, n. 3, p. I3-2I, (jul-set) I993.

NEVES JUNIOR, I. J. Contribuição do contrato de gestão em instituições financeiras para o processo de aprendizagem organizacional. Brasília, 2003. Dissertação (Mestrado em Gestão do Conhecimento da Tecnologia da Informação) - Universidade Católica de Brasília. 
ORSOLINI, R. Alocação de capital: um enfoque de avaliação de desempenho ajustado ao risco em bancos. São Paulo, 2000. Dissertação (Mestrado em Ciências Contábeis) - Faculdade de Economia, Administração e Contabilidade, Universidade de São Paulo.

PONTES, B. R. Avaliação de desempenho: nova abordagem. 6. ed. São Paulo: LTR, I996.

SICHIERI, R. et al. Fatores associados ao padrão de consumo alimentar da população brasileira urbana. Disponível em: <http://www.scielo.br/scielo.php?script=sci_arttext\&pid=SoIO23IIX2003000700006>. Acesso 22 jun. 2005.

WELSH, G. A. Orçamento empresarial. 4. ed. São Paulo: Atlas, I983.

WRIGHT, P. et al. Administração estratégica: conceitos. São Paulo: Atlas, 2000.

\section{TRAMITAÇÃO}

Recebido em 7/11/2006

Aprovado em 26/3/2007 
Copyright of Revista de Administração Mackenzie is the property of Universidade Presbiteriana Mackenzie, RAM-Revista de Administracao Mackenzie and its content may not be copied or emailed to multiple sites or posted to a listserv without the copyright holder's express written permission. However, users may print, download, or email articles for individual use. 